\title{
Design of p-shaped microstrip patch antenna for wireless communication systems
}

\author{
Raad H. Thaher, Noor Baqir Hassan \\ Department of Electric, College of Engineering, Al-Mustansiryah University, Iraq
}

\begin{tabular}{l}
\hline \hline Article Info \\
\hline Article history: \\
Received Oct 1, 2018 \\
Revised Dec 10, 2018 \\
Accepted Jan 25, 2019 \\
\hline
\end{tabular}

\section{Keywords:}

Microstrip antenna

P-patch

Radiation pattern

UWB

VSWR

\begin{abstract}
A P-shaped microstrip patch antenna is proposed and studied to obtain operating bandwidth of (5.883-9.9) GHz. Then the antenna is extended by etching slots in the ground plane to be $(5.73-10.234) \mathrm{GHz}$ and gain varies from $2.809 \mathrm{dBi}$ to $4.947 \mathrm{dBi}$. The antenna is installed on FR-4 substrate having relative dielectric constant of $\varepsilon_{r}=4.3$ and loss tangent of 0.02 . The antenna size is $(30 \times 30 \times 1.6) \mathrm{mm}^{3}$ simulation results were obtained using CST software 2016. The proposed was fabricated and tested by vector network analyzer VNA and noted reasonable agreement between simulated and measured result.
\end{abstract}

Copyright $\odot 2019$ Institute of Advanced Engineering and Science. All rights reserved.

Corresponding Author:

Noor Tamimi,

Department of Electrical Engineering,

AL-Mustansiryah University, Iraq, Baghdad.

Email: noorbaqir2018@gmail.com

\section{INTRODUCTION}

Antenna become important part of electric devices in the field of wireless communication system since $1888[1,2]$. In the recent years the development in modern wireless communication system requires low profile, light weight, high gain and high efficiency characteristics like radar, mobile, satellite, GPS and etc.. Microstrip antenna satisfies such requirements [3, 4]. It has various attractive feature such as, light weight, low cost, conform ability to shaped surface, compatibility with integrated circuitry and thin profile antennas that are capable of maintaining high performance over a wide spectrum of frequencies [5-8]. Despite the many advantages of typical microstrip antenna they also have limitations, narrow bandwidth, low gain, and relatively large size [7, 9].

The ultra-wideband (UWB) is an emerging radio technology that has received much attention. UWB communication systems can be broadly defined as any communication system whose instantaneous bandwidth is many times greater than the minimum required to deliver particular information and it plays a dominate role in wireless communication system [2, 10]. In 2002, FCC (Federal communication commission) allowed (3.1- 10.3) GHz unlicensed become a variable for commercial applications and military [11, 12]. This technology has more advantage low consumption, high data rate transmission, reducing the multipath effect which may cause fading and high degree of reliability and accuracy $[1,2]$. These advantages made it required in many application such as wireless communication system and biomedical application [2].

To widen the bandwidth, there are more suggestion to design UWB antenna. Gagndeep Sahu, and Tejaswini R. Choudri in [10] presented that, proximity coupling with array triangular shaped patch of different size has been used to overcome on low bandwidth case resultant from difficulties in impedance matching and low coupling levels. Hafid Tizyi et al. in [2] presented that, fractal shape with progressive evaluation of the impedance technique between the feed and radiation element has been used to achieve increasing in bandwidth. Raad H. Thaher in [1] presented that, a circular microstrip antenna with partial 
ground plane has been used to achieve suitable antenna for UWB. Mohamed A. Hassanien et al. in [5] presented that, a rectangular microstrip patch antenna with U-shape slot in the patch and a finite ground plane has been used to achieve antenna for UWB application. Raad H. Thaher, and Saif Nadhim Alsaidy in [12] presented that irregular pentagonal patch antenna has been used instead of regular pentagonal patch with partial ground plane to overcome the dual bandwidth and obtain single band UWB.

In proposed antenna is used simple shape in patch plane is P-shape and partial ground plane with some slots to improve the characteristics of antenna as would explain in next sections. The characteristic impedance can be expressed by [7].

$$
Z c=\frac{120 \pi}{\sqrt{\varepsilon_{\text {reff }}}\left[\frac{W_{f}}{h}+1.393+0.667\left(\frac{W_{f}}{h}+1.444\right)\right]}
$$

where

$\varepsilon_{\text {reff }}$ is effective dielectric constant

$W_{f}$ is the feeder width

$h$ is the substrate height

This proposed antenna is the first step of design 2-element P-shaped microstrip antenna array which was mentioned in the research paper [13], and it is beneficial for applications located at frequency bands were allocated in U.S. and European such as, Radar, Mobile, amateur radio, police speed radar, public and privet fixed microwave, unlicensed industrial, scientific, and medical communication devices [14, 15].

\section{THE PROPOSED ANTENNA}

Figure 1 shows the P-patch antenna geometry with dimensions. The substrate is chosen for this antenna is FR-4 that has dielectrical constant $\varepsilon_{r}=4.3$ and loss tangent of 0.02 with thickness $\mathrm{h}=1.6 \mathrm{~mm}$ and area $(33 \times 30) \mathrm{mm}^{2}$. Now let us make the parametric study of the proposed antenna.

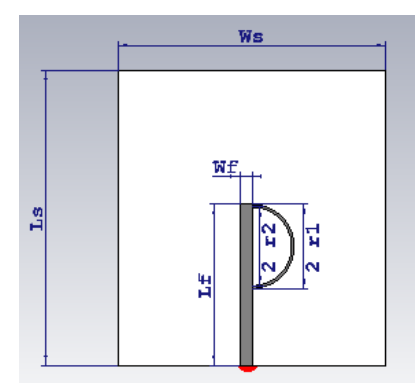

(a)

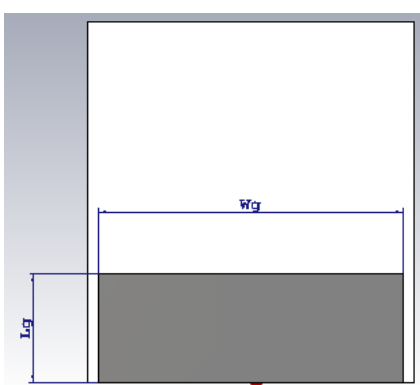

(b)

Figure 1. The p-patch antenna (a) The front view (b) back view

\subsection{Effect of ground length $\mathrm{Lg}$}

The effect changing the length of ground $\mathrm{Lg}$ appears in Figure 2 it is found that $\mathrm{Lg}=10 \mathrm{~mm}$ give preferable BW from (5.883-9.9) $\mathrm{GHz}$ with (reflection coefficient) $S_{11} \leq-10 \mathrm{~dB}$.

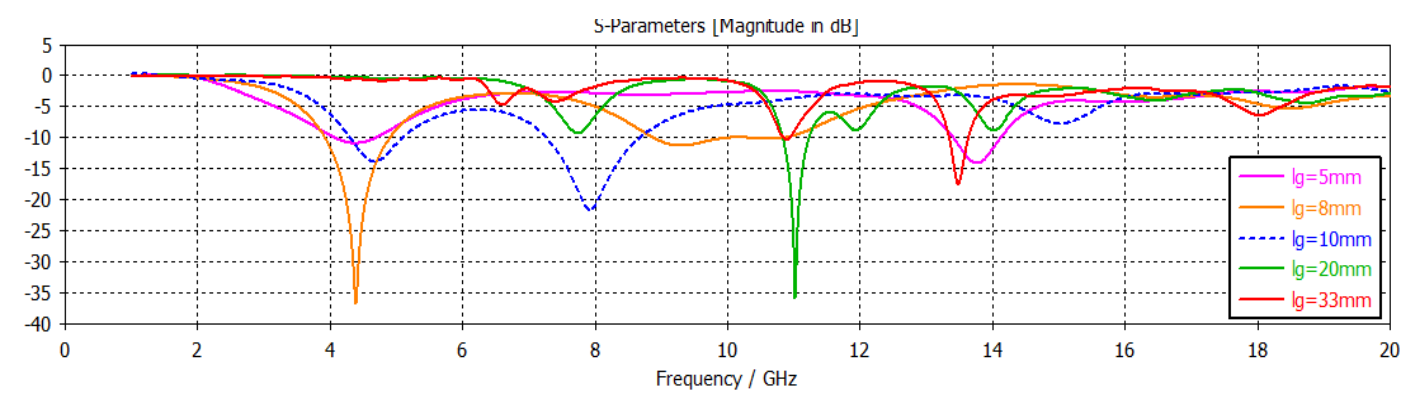

Figure 2. Effect of ground length Lg 


\subsection{Effect of ground width $\mathrm{Wg}$}

The effect changing the width of ground $\mathrm{Wg}$ appear in Figure 3 it is found that $\mathrm{Wg}=28 \mathrm{~mm}$ give preferable BW from (5.883- 9.9) $\mathrm{GHz}$ with reflection coefficient $S_{11} \leq-10 \mathrm{~dB}$.

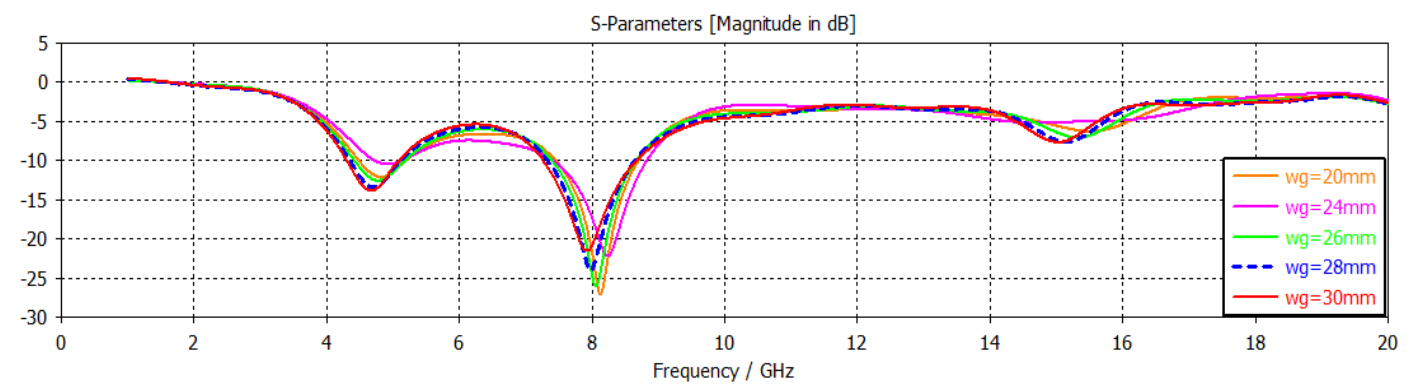

Figure 3. Effect of ground width Wg

\subsection{Effect of feeder length $L f$}

The effect changing the length of feeder Lf appear in Figure 4 it is found that $\mathrm{Lf}=18 \mathrm{~mm}$ give preferable BW from (5.883-9.9) GHz with reflection coefficient $S_{11} \leq-10 \mathrm{~dB}$.

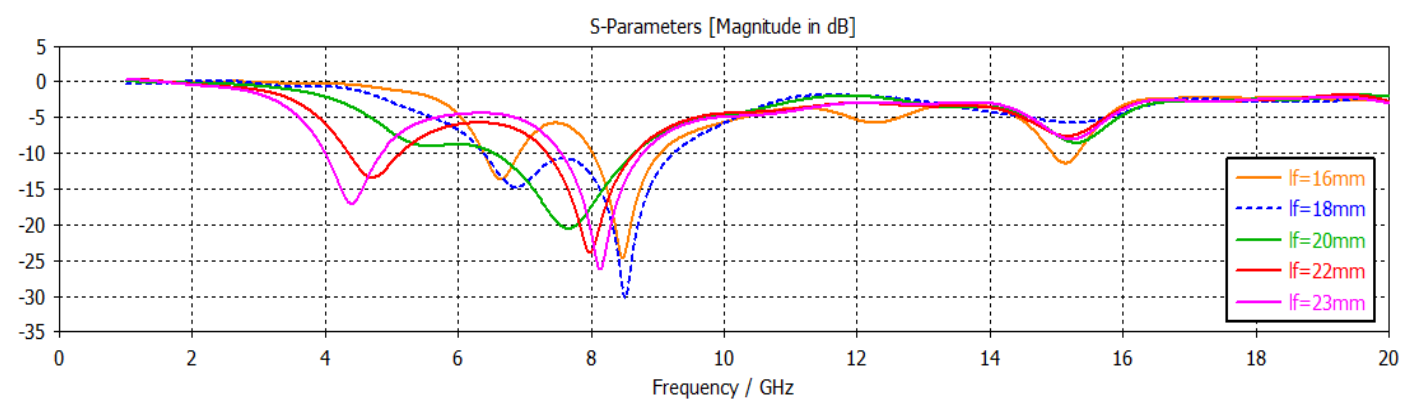

Figure 4. Effect of feeder length $\mathrm{Lf}$

\subsection{Effect of feeder width Wf}

The effect changing the feeder width Wf appear in Figure 5 it is found that $\mathrm{Wf}=1.4 \mathrm{~mm}$ give preferable BW from $(5.883-9.9) \mathrm{GHz}$ with reflection coefficient $S_{11} \leq-10 \mathrm{~dB}$.

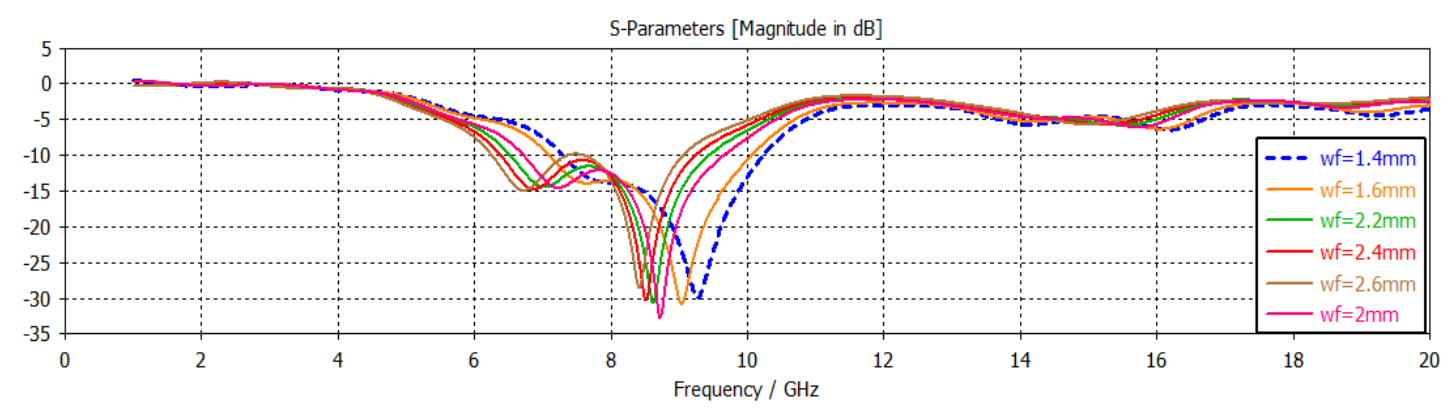

Figure 5. Effect of feeder width Wf

\subsection{Effect of inner radius $r 2$}

The effect changing the inner radius $\mathrm{r} 2$ appear in Figure 6 it is found that $\mathrm{r} 2=4.4 \mathrm{~mm}$ give preferable BW from (5.883-9.9) $\mathrm{GHz}$ with reflection coefficient $S_{11} \leq-10 \mathrm{~dB}$. 


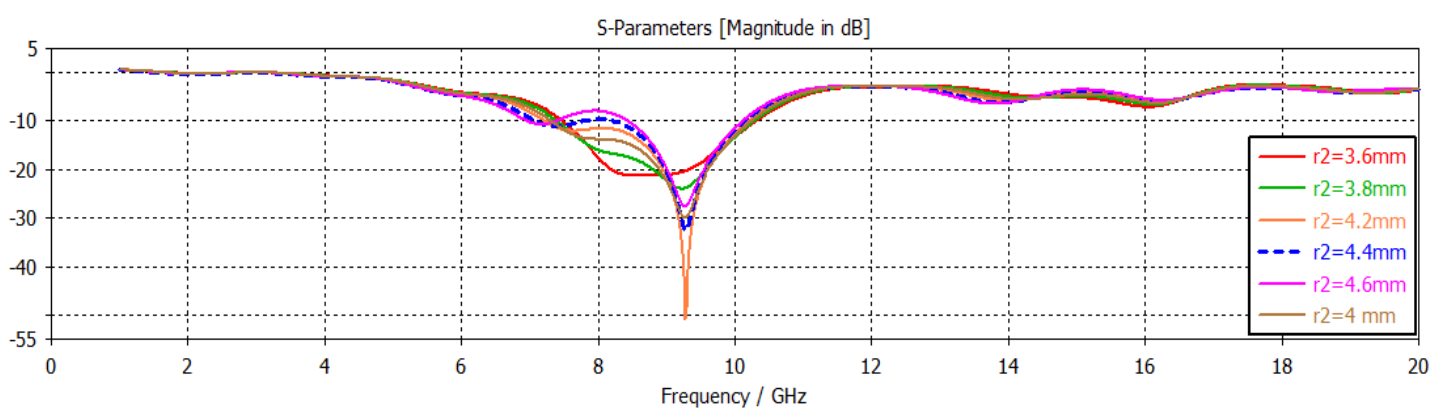

Figure 6. Effect of inner radius r2

\subsection{Effect of outer radius $r 1$}

The effect changing the outer radius $\mathrm{r} 1$ appear in Figure 7 it is found that $\mathrm{r} 1=4.7 \mathrm{~mm}$ give preferable BW from (5.883-9.9) $\mathrm{GHz}$ with reflection coefficient $S_{11} \leq-10 \mathrm{~dB}$.

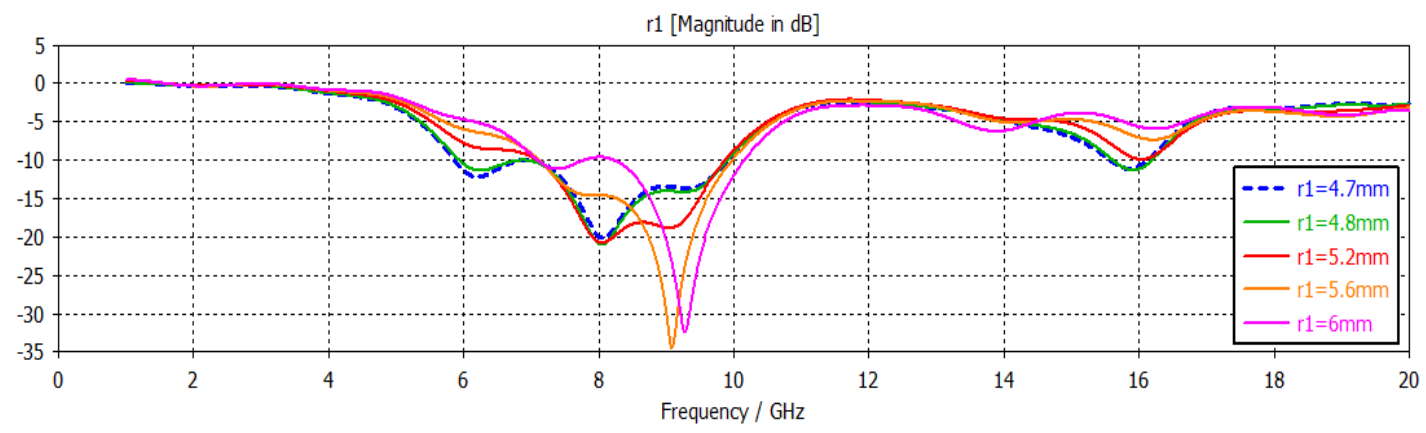

Figure 7. Effect of outer radius $\mathrm{r} 1$

\subsection{Effect of making slots in ground plane}

For improve the antenna characteristics, some slots are etched in ground. The first slot at middle of ground plane with dimensions $(\mathrm{X} 1=2 \times \mathrm{X} 2=2.8) \mathrm{mm}^{2}$ that give $\mathrm{BW}$ from $(5.75-10.234) \mathrm{GHz}$ with $S_{11} \leq-$ $10 \mathrm{~dB}$. Then 4 slots are etched on the two sides of the middle slot with dimensions $(\mathrm{X} 3=2.8 \times \mathrm{X} 4=0.5) \mathrm{mm}^{2}$ with space between each other equal to $\mathrm{X} 5=2.8 \mathrm{~mm}$, getting multiband from $(5.674-6.97) \mathrm{GHz}$ and from (7.54-10.234) GHz.

To improve the BW and to overcome the multiband case, rectangular slot made on the left of the ground with dimension $(\mathrm{Y}=4.5 \times \mathrm{Z}=8.5) \mathrm{mm}^{2}$ as shown in Figure 8 It is obvious give best $\mathrm{BW}$ from (5.674 10.253) $\mathrm{GHz}$.

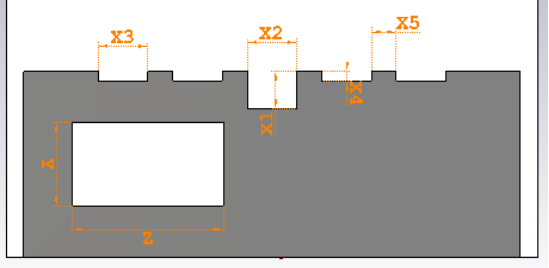

(a)

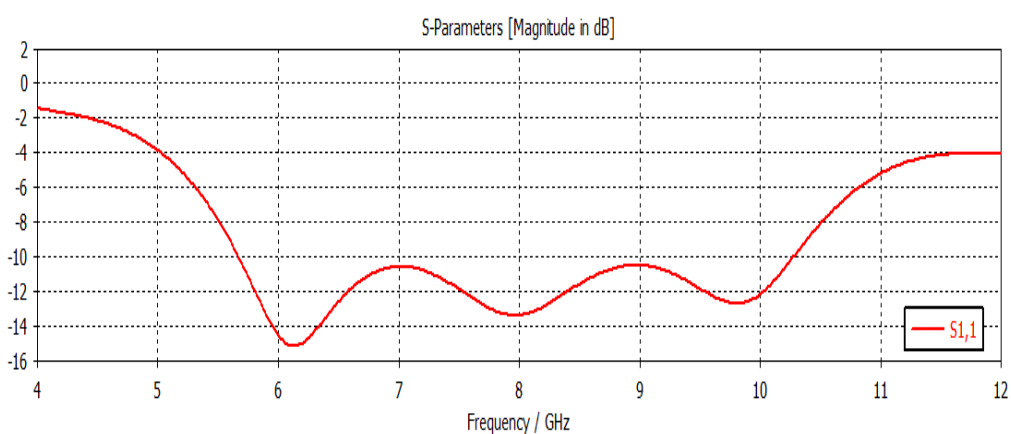

(b)

Figure 8. (a) 5 Slot and rectangular slot in ground. (b) Effect of 5 slot and rectangular slot in ground 
Table 1 shows the optimum parameter values of the modified antenna.

Table 1. Antenna Parameter Values

\begin{tabular}{cccc}
\hline Parameter & Value $(\mathrm{mm})$ & Parameter & Value $(\mathrm{mm})$ \\
\hline $\mathrm{Ls}$ & 33 & $\mathrm{X} 1$ & 2 \\
$\mathrm{Ws}$ & 30 & $\mathrm{X} 2$ & 2.8 \\
$\mathrm{Lg}$ & 10 & $\mathrm{X} 3$ & 2.8 \\
$\mathrm{Wg}$ & 28 & $\mathrm{X} 4$ & 0.5 \\
$\mathrm{Lf}$ & 18 & $\mathrm{X} 5$ & 2.8 \\
$\mathrm{Wf}$ & 1.4 & $\mathrm{Y}$ & 4.5 \\
R1 & 4.7 & $\mathrm{Z}$ & 8.5 \\
R2 & 4.4 & & \\
\hline
\end{tabular}

The proposed patch antenna is fabricated. Figure 9 shows the photograph of the fabricated P- shaped antenna.

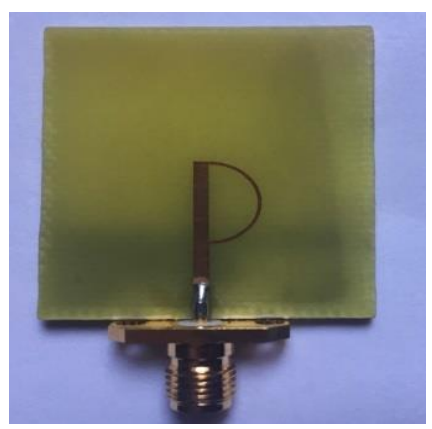

(a)

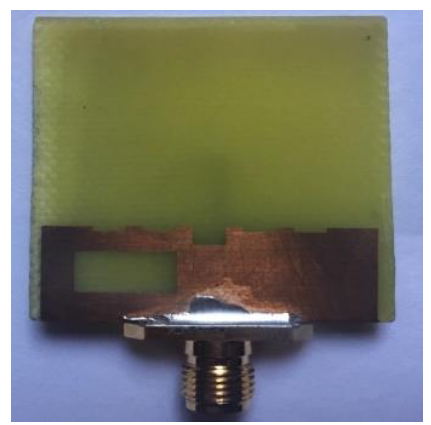

(b)

Figure 9. Fabricated P-shape patch antenna (a) Top view (b) back view

\section{CHARACTERISTICS OF THE PROPOSED P-PATCH ANTENNA}

Now let us describe the characteristics of the proposed antenna with optimum parameters values.

\subsection{S-parameter and VSWR}

The fabricated antenna is shown in figure (9) has simulated results that obtained on it from CST (Computer simulation Technology) and measured results tested by VNA (vector network analyzer). Figure 10 shows simulated and measured return loss variation with frequency. Where $S_{11}=10 \log \Gamma(\Gamma$ is the reflection coefficient). However the voltage standing wave ratio (VSWR) against frequency is shown in Figure 11 .

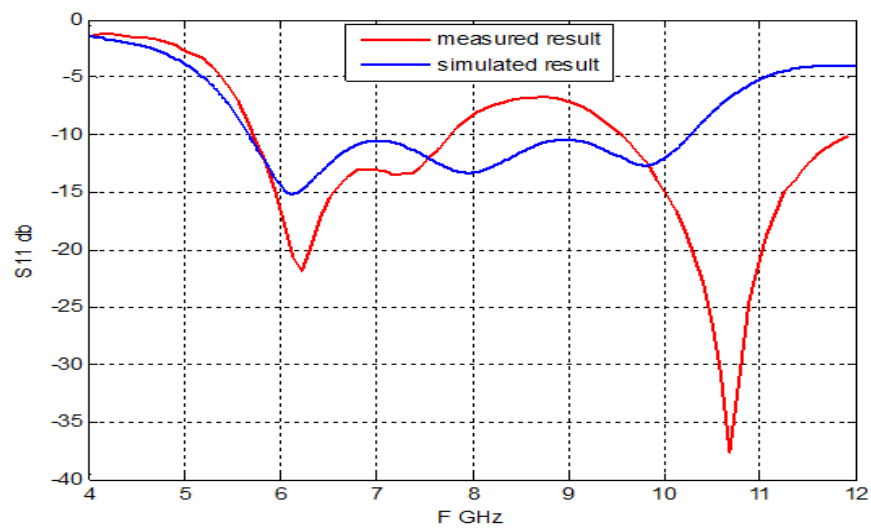

Figure 10. S-parameter versus frequency for measured and simulated results comparison 


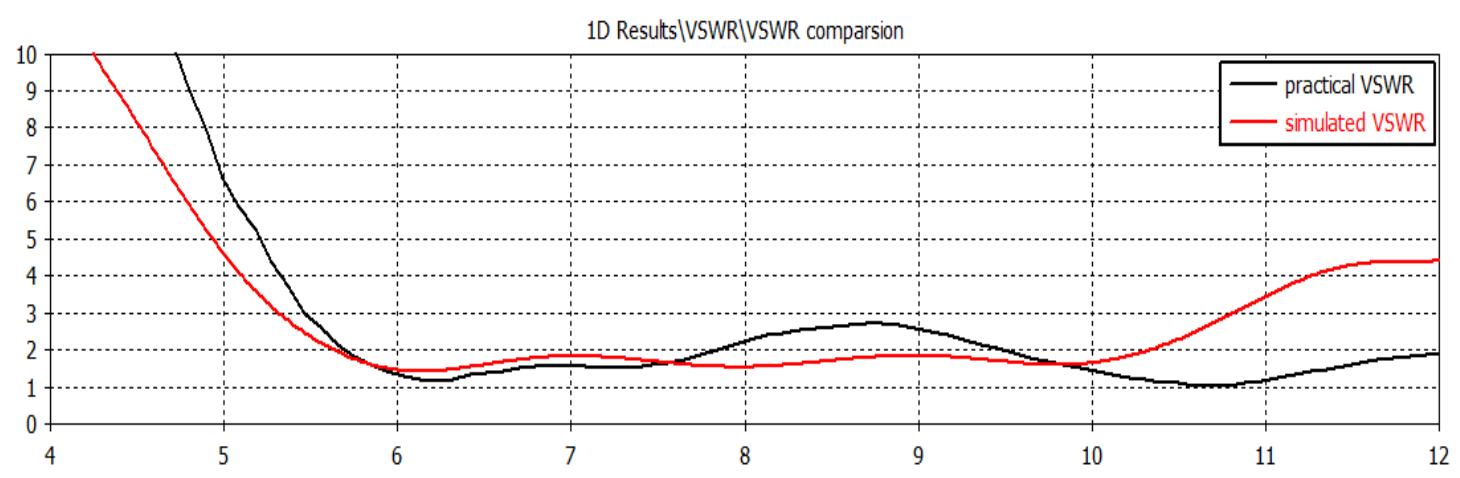

Figure 11. Return loss versus frequency

The VSWR is the ratio of the peak amplitude of a standing wave to minimum amplitude of standing wave [12] also it is a measure of matching between antenna and transmission line. VSWR is function to the reflection coefficient and the acceptable VSWR $<<2$ in pass band.

$$
V S W R=\frac{1+|\Gamma|}{1-|\Gamma|}=\frac{V \max }{V \min }
$$

where

$\Gamma$ is reflection coefficient [6].

$$
\Gamma=\frac{\text { Reflection voltage }}{\text { Incident voltage }}=\frac{Z_{\mathrm{R}}-Z o}{Z_{\mathrm{R}}+Z o}
$$

where

$\mathrm{Z}_{\mathrm{R}}=$ Load impedance.

$\mathrm{Zo}=$ Characteristic impedance [6].

It is noted that, there is a good agreement between measured results and simulated results with some errors due to the fabrication errors which include discontinuity and $\varepsilon_{r}$ in addition to difficulty of manufacturing the antenna.

\subsection{Antenna gain}

The simulated gain for the p-patch antenna appears in Figure 12. The gain varies from $2.809 \mathrm{dBi}$ to $4.947 \mathrm{dBi}$.

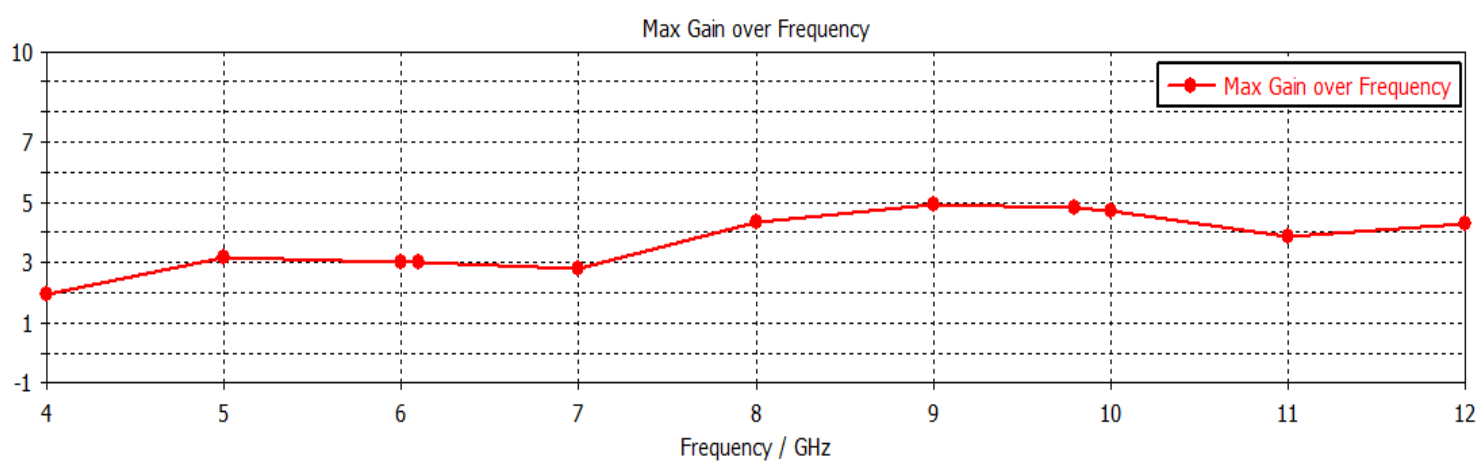

Figure 12. Gain for the p-patch antenna

\subsection{Current Distribution}

P-patch antenna current distribution is shown in Figure (13) at frequencies $(6.1,8,9.7987) \mathrm{GHz}$. Figure 13(a) shows the current distribution at frequency (6.1) $\mathrm{GHz}$ it has maximum current $(90.1 \mathrm{~A} / \mathrm{m})$. Figure 13(b) shown the current distribution at frequency (8) $\mathrm{GHz}$ it has maximum current $(95.1 \mathrm{~A} / \mathrm{m})$. Figure 13(c) shown the current distribution at frequency (9.7987) GHz it has maximum current (105A/m). 


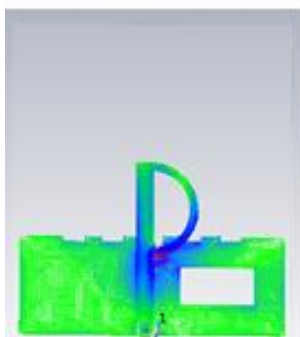

(a)

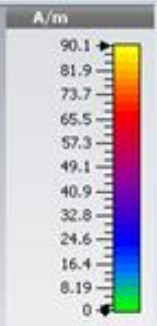

19

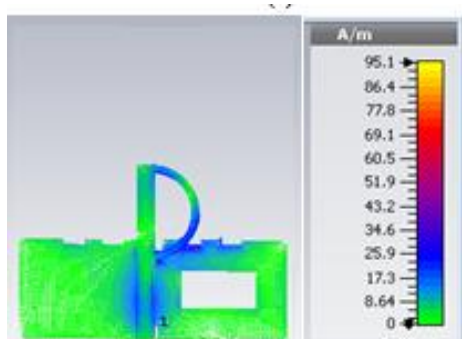

(b)

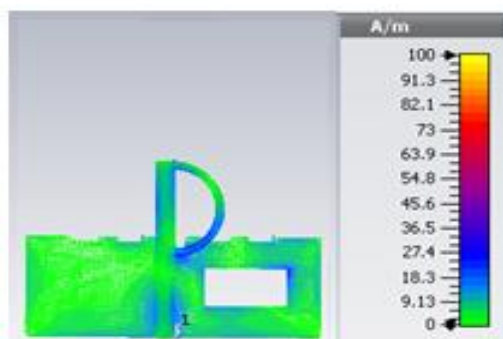

(c)

Figure 13. Currents distributions for following frequencies (a) $6.1 \mathrm{GHz}$; (b) $8 \mathrm{GHz}$; (c) $9.7987 \mathrm{GHz}$

\subsection{Far Field Radiation Pattern}

Figure 14 shows the simulated radiation patterns of the proposed antenna in E-plane (Y-Z plane) and H-plane (X-Z plane) for three frequencies within band which are $(6.1,8,9.7987) \mathrm{GHz}$. Figure 14(a) shows the radiation pattern at $6 \mathrm{GHz}$, in the E-plane, the magnitude of main lobe is (1.26) $\mathrm{dBi}$ in the direction $\left(11.0^{\circ}\right)$ with the angular width $(3 \mathrm{~dB})$ is $\left(109.3^{\circ}\right)$, in the $\mathrm{H}$-plane, the magnitude of main lobe is $(3.08) \mathrm{dBi}$ in direction $\left(177^{\circ}\right)$ with the angular width $(3 \mathrm{~dB})$ is $\left(78.9^{\circ}\right)$. Figure $14(\mathrm{~b})$ shows the radiation patterns at $8 \mathrm{GHz}$, in the E-plane, the magnitude of main lobe is $(0.507) \mathrm{dBi}$ in the direction $\left(74^{\circ}\right)$ with the angular width $(3 \mathrm{~dB})$ is $\left(236.8^{\circ}\right)$, in the $\mathrm{H}$-plane, the magnitude of main lobe is $(4.25) \mathrm{dBi}$ in direction (13.6) with the angular width $(3 \mathrm{~dB})$ is $\left(65.1^{\circ}\right)$. Figure $14(\mathrm{c})$ shows the radiation patterns at $9.7987 \mathrm{GHz}$, in the E-plane, the magnitude of main lobe is $(1.45) \mathrm{dBi}$ in the direction $\left(70.0^{\circ}\right)$ with the angular width $(3 \mathrm{~dB})$ is $\left(114.2^{\circ}\right)$, in the $\mathrm{H}$-plane, the magnitude of main lobe is $(4.17) \mathrm{dBi}$ in direction $\left(154^{\circ}\right)$ with the angular width $(3 \mathrm{~dB})$ is $\left(71.9^{\circ}\right)$.

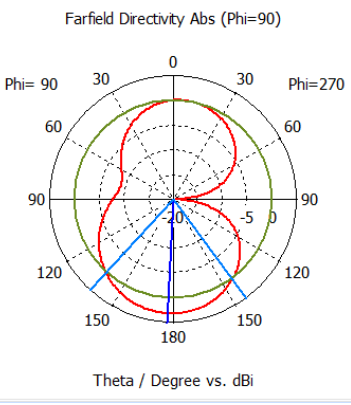

E-Field

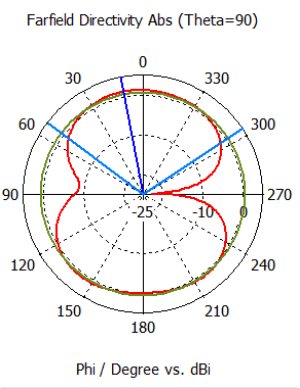

H-Field

(a)

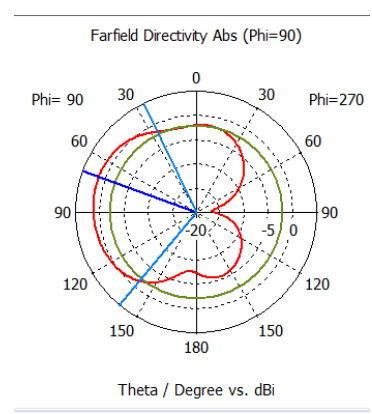

E-Field

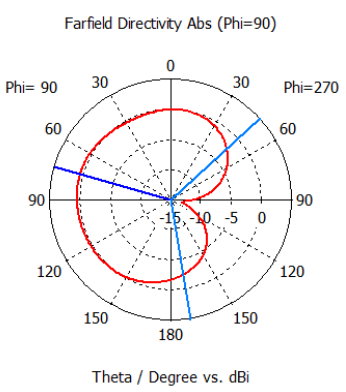

E-Field

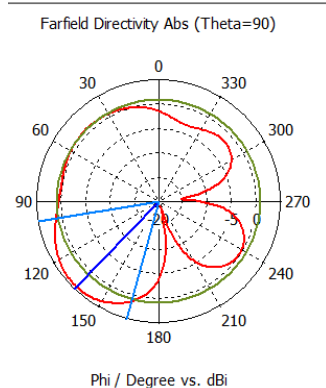

H-Field

(b)

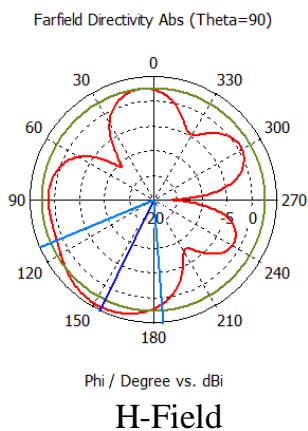

(c)

Figure 14. Far field radiation pattern for (a) $6.1 \mathrm{GHz}$; (b) $8 \mathrm{GHz}$; (c) $9.7897 \mathrm{GHz}$

\subsection{D Radiation Pattern}

Figure 15 shows the simulated 3D radiation pattern of the p-patch antenna at frequencies $(6.1,8,9.7987) \mathrm{GHz}$. These plots appears maximum directivity $(3.08,4.43$ and 4.83$) \mathrm{dBi}$ for frequencies (6.1, 8, and 9.7987) GHz respectively.

Design of P-shaped microstrip patch antenna for wireless communication systems (Raad H. Thaher) 


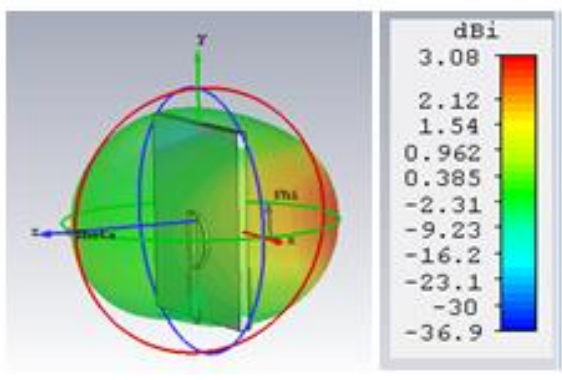

(a)

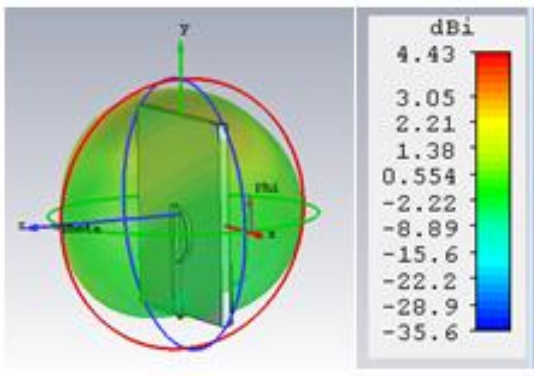

(b)

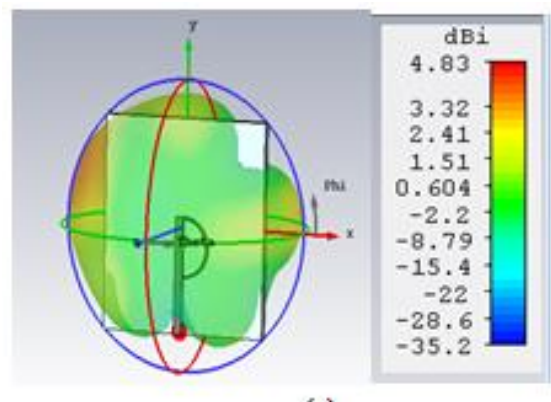

(c)

Figure 15. 3D radiation pattern for the proposed antenna for (a) $6 \mathrm{GHz}$; (b) $8 \mathrm{GHz}$; (c) $9.7987 \mathrm{GHz}$

\subsection{Group delay}

Group delay is an important parameter in UWB antenna design; it gives the distortion of the transmitted pulses in UWB communications [2]. The antenna should be able to transmit the electrical pulse with minimum distortion [12]. Figure 16 shows the group delay for the proposed antenna, it varies from 0.25 $\mathrm{ns}$ to $-0.25 \mathrm{~ns}$.

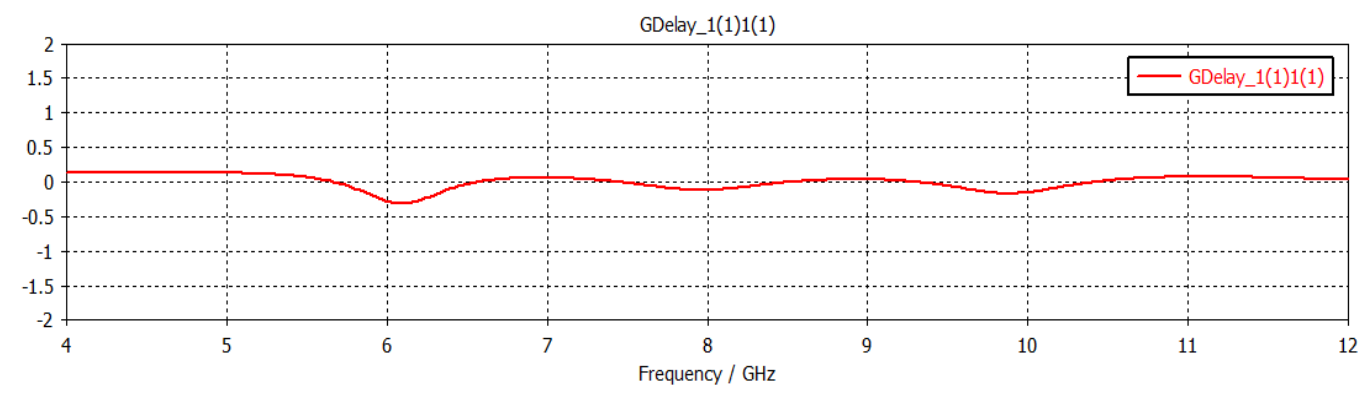

Figure 16. Group delay for the proposed antenna

\section{CONCLUSION}

The P-shaped patch antenna was designed and simulated results were obtained for optimum values of variables $(\mathrm{Lf}, \mathrm{Lg}, \mathrm{r} 1, \mathrm{r} 2)$. It is found that adding slots in the ground plane will enlarge the band width from (5.883-9.9) GHz to (5.674-10.234) GHz resulting gain of $2.809 \mathrm{dBi}$ to $4.947 \mathrm{dBi}$. This antenna can be used for applications were placed within the U.S. and European frequency bands allocated such as radar, mobile and other wireless communication. The current distribution of such antenna is considered at frequencies within the operation bandwidth which gives maximum current of $90.1 \mathrm{~A} / \mathrm{m}, 95.1 \mathrm{~A} / \mathrm{m}$, and $105 \mathrm{~A} / \mathrm{m}$ at $6.1 \mathrm{GHz}, 8 \mathrm{GHz}$, and $9.7987 \mathrm{GHz}$ respectively. Also, the 3D radiation pattern shows that the antenna gives maximum directivity of $4.83 \mathrm{dBi}$ at $9.7987 \mathrm{GHz}$. The antenna size is $(30 \times 30 \times 1.6) \mathrm{mm}^{3}$ with FR-4 substrate. The fabricated antenna is tested by VNA and compared the practical result with the simulation result and concluded reasonable agreement between results. 


\section{REFERENCES}

[1] R. H. Thaher, "Single and Multiband UWB circular patch antenna for wireless communication application," American journal of Electromagnatics and Applications, vol. 3, pp. 16-23, 2015.

[2] H. Tizyi, et al., "Miniaturized Ultra Wideband Microstrip Antenna Based on a Modified Koch Snowflake Geometry for Wireless Applications," American Journal of Electromagnetics and Applications, vol. 3, 2015.

[3] M. T. I. Huque, et al., "Design and performance analysis of microstrip array anteena with optimum parameters for X-band applications," IJACSA, vol. 2, pp. 81-87, 2011.

[4] A. K. Jassim and R. H. Thaher, "Enhance Gain of Broadband Elliptical Microstrip Patch Array Antenna with Mutual Coupling for Wireless Communication," Indonesian Journal of Electrical Engnineering and computer Science, vol. 13, pp. 217-255, Jan 2019.

[5] M. A. Hassanien, et al, "Compact rectanguler U-shaped slot microstrip patch antenna for UWB applecations," IEEE, MECAP, vol. 20, pp. 10, 2010.

[6] Y. S. Khraisat, "Design of 4 elements rectangular microstrip patch antenna with high gain for $2.4 \mathrm{GHz}$ applications," Modern Applied Science, vol. 6, pp. 68-74, Jan 2012.

[7] C. A. Balanis, "Moderen Antenna Handbook," John Wiley and sons, 2008.

[8] R. H. Thaher and Z. S. Jamil, "Design of Dual Band Microstrip Antenna for Wi-Fi and WiMax Aplication," TELKOMNIKA Telecommunication Computing Electronics and Control, vol. 13, pp. 125-132, Jun 2015.

[9] E. Vaishali R., et al., "Design of microstrip patch antenna array," International Journal of Engineering Research and Technology, vol. 2, Dec 2013.

[10] G. Sahu, et al., "A UWB triangular shape, trangular patch antenna array type antenna for 3G mobile communication in India," International Journal of Computing Science and Communication Technologies, 2012.

[11] Firist Report and order, "Federal Communication Commission (FCC)," Feb 2002.

[12] R. H. Thaher, et al., "New Compact Pentagonal Microstrip Patch Antenna for Wireless Communications Application," American Journal of Electromagnetics and Applications, vol. 3, pp. 53-64, 2015.

[13] R. H. Thaher and N. B. Hassan, "Proposed P-shaped Microstrip Antenna Array for Wireless Communication Applications," TELKOMNIKA Telecommunication Computing Electronics and Control, vol. 16, Dec 2018.

[14] "United States Frequency Allocation," National Telecomination and Information Administration, Oct 2003.

[15] "The European table of frequency allocations and application in the frequency range $8.3 \mathrm{kHz}$ to $3000 \mathrm{GHz}$," Electronic Communication Committee (ECC) within the European Conference of Postal and Telecommunication Administration (CEPT), Jun 2016. 